\title{
EXPERIÊNCIA DO GRUPO PET-ELÉTRICA UFPB COM O ENSINO A DISTÂNCIA: ADAPTAÇÃO DO ENSINO EM TEMPOS DE PANDEMIA
}

\author{
Miguel Marques Ferreira - miguel.ferreira@ cear.ufpb.br \\ Maria Heloisa de Pietra Silva - maria.silva@cear.ufpb.br \\ Tiago dos Santos Paiva - tiago.paiva@ cear.ufpb.br \\ Diana Bezerra Correia Lima - diana.lima@ cear.ufpb.br \\ Euler Cássio Tavares de Macedo - euler@ cear.ufpb.br \\ Universidade Federal da Paraíba \\ Cidade Universitária, s/n - Castelo Branco III \\ 58051-085 - João Pessoa - Paraíba
}

\begin{abstract}
Resumo: Devido ao rápido surgimento de uma pandemia no ano de 2020, causada pelo novo coronavírus, foi necessário que a população de um modo geral, em especial a comunidade acadêmica, tomassem medidas de isolamento e distanciamento social. Devido à impossibilidade momentânea de se frequentar aulas presenciais, as universidades e ambientes de aprendizado se deparam com o novo desafio de adaptar o ensino às circunstâncias atuais. Desse modo, neste trabalho busca-se analisar o uso do Ensino a Distância, suas vantagens e desvantagens, tomando como base o curso online oferecido pelo grupo PET-Elétrica UFPB, de capacitação sobre o software InDesign, após avaliação dos dados obtidos por meio de questionários de satisfação online.
\end{abstract}

Palavras-chave: Ensino a Distância. Pandemia. Programa de Educação Tutorial - PET. Educação. Isolamento Social.

\section{INTRODUÇÃ̃}

O primeiro semestre do ano de 2020 foi fortemente marcado pelo desenvolvimento de uma pandemia, causada pelo Coronavírus da Síndrome Respiratória Aguda Grave 2 (SARS-CoV2), popularmente conhecido como coronavírus. O primeiro paciente conhecido desenvolveu sintomas em 8 de dezembro de 2019 (COHEN; NORMILE, 2020). De acordo com a Organização Pan-Americana de Saúde, a Organização Mundial da Saúde (OMS) declarou, em 30 de janeiro de 2020, que o surto da doença causada pelo novo coronavírus constitui uma Emergência de Saúde Pública de Importância Internacional - o nível mais alto de alerta da Organização, de acordo com o Regulamento Sanitário Internacional (RSI). Em 11 de março de 2020, a COVID-19 foi caracterizada pela OMS como uma pandemia.

Segundo o Ministério da Saúde, a transmissão da doença se dá pelo contato com uma pessoa infectada, podendo acontecer por meio de apertos de mão, espirros e tosses, e até objetos ou superfícies contaminadas. Tendo em vista os limites dos sistemas de saúde em todo o 
planeta, os países afetados adotaram medidas como distanciamento social e o fechamento de escolas, universidades e locais de trabalho. O objetivo dessas estratégias é reduzir a transmissão, e assim, reduzir o pico de intensidade da pandemia (ANDERSON et al, 2020), diminuindo o risco de colapsar os sistemas de saúde, e ganhando, então, tempo para desenvolver tratamentos e vacinas (KISSLER et al, 2020).

Embora as medidas de isolamento e distanciamento social sejam eficazes no controle da pandemia (COWLING et al, 2020), elas têm um certo custo para a educação e saúde mental das pessoas (WEST et al, 2020). Muitos indivíduos em quarentena experimentaram problemas de saúde mental de curto e longo prazo, incluindo estresse, insônia e exaustão emocional (BROOKS et al, 2020). Deste modo, tendo em vista os desafios em tempos de pandemia devido ao isolamento e distanciamento social, o ambiente universitário se depara com a necessidade de desenvolver alternativas para administrar o ensino em Instituições de Ensino Superior (IES), sendo uma das alternativas mais utilizadas o Ensino a Distância (EaD).

De acordo com Santos (2006), Educação à Distância é um sistema tecnológico de comunicação bidirecional, que substitui o contato pessoal professor/aluno, como meio preferencial de ensino, pela ação sistemática e conjunta de diversos recursos didáticos e pelo apoio de uma organização e tutoria, possibilitando assim a aprendizagem independente e flexível dos alunos.

Algumas vantagens do $\mathrm{EaD}$ são a autonomia no estudo, a individualização da aprendizagem, e o custo reduzido por estudante (SANTOS, 2006), enquanto que entre as desvantagens, pode-se citar a impossibilidade do acesso por parte da parcela da população que não possui acesso a internet e computadores.

Este trabalho visa, então, fazer uma análise da atividade que o Programa de Educação Tutorial em engenharia elétrica da Universidade Federal da Paraíba (PET-Elétrica UFPB) desenvolveu, em busca de contornar os desafios referentes ao ensino, impostos pelo distanciamento social.

\section{REFERENCIAL TEÓRICO}

Segundo o educador Paulo Freire (1996), a ação de ensinar não se resume apenas a transferir conhecimento, ela engloba a criação de oportunidades e a produção do saber. Assim, a relação entre ensino e aprendizagem pode ser estabelecida de diferentes maneiras, de modo que o método utilizado para o ensino possa ser adaptado, permitindo que a aprendizagem seja alcançada da melhor forma possível.

O mundo tem passado por transformações rápidas, trazendo o desafio de inovar os métodos em diversas áreas, afim de acompanhar as mudanças que estão acontecendo. Atualmente o mundo está passando por uma crise causada pela pandemia do novo coronavírus. Diante disso, as medidas de isolamento social causam um impacto direto na educação. Segundo a Organização das Nações Unidas para a Educação, a Ciência e a Cultura (UNESCO), 190 países fecharam suas escolas e universidades, atingindo mais de 1,5 bilhões de alunos. Esse quantitativo representa aproximadamente $90 \%$ do total de estudantes de todo o mundo. A UNESCO ainda reforça a necessidade de valorizar a educação em tempos difíceis como esse, 
fortalecendo a criação de novas oportunidades de aprendizagem que se adaptem a essa nova realidade.

Devido a esse cenário, escolas e universidades têm adotado a modalidade de ensino a distância, na tentativa de diminuir os prejuízos aos alunos e de dar continuidade a suas atividades em meio a pandemia. No Brasil, a substituição de aulas presenciais por atividades à distância foi prorrogada até o dia 31 de dezembro de 2020 pelo Ministério da Educação (MEC), a partir da publicação da portaria No 544 no Diário Oficial da União no dia 16 de junho se 2020.

Além disso, o Conselho Nacional de Educação (CNE), mediante às medidas de distanciamento social tomadas devido ao coronavírus, aprovou diretrizes que sugere que estados e municípios busquem alternativas em atividades não presenciais para o cumprimento da carga horária de cada sistema. Essa nova circunstância apresenta um desafio para alunos e professores, pois muitos estão tendo pela primeira vez o contato com o ensino a distância. Materiais como vídeo aulas, programas em redes sociais e atividades complementares remotas precisam ser criadas e disponibilizadas aos alunos e, para isso, será necessário um programa de capacitação para professores e alunos. Esse fato evidencia ainda mais a importância das novas ferramentas de gestão educacional que serão utilizadas nesse tempo de incertezas.

O Ensino a Distância e o ensino presencial, embora possuam características únicas, não competem entre si. Elas são direcionadas para interesses, objetivos e realidades diferentes. A adesão de aulas à distância por escolas e universidades que trabalham com atividades presenciais surge como opção para suprir a necessidade causada pelo distanciamento social. Entretanto, a modalidade de ensino a distância já possui uma base bastante sólida no Brasil. Segundo dados do último CensoEAD.BR, referente ao ano de 2018 e publicado pela Associação Brasileira de Educação à Distância (ABED), o número de alunos matriculados em todas as modalidades de EAD cresceu mais de $20 \%$ em comparação ao censo do ano anterior. $\mathrm{Na}$ graduação, os números também evidenciam esse crescimento. De acordo com o censo da educação superior de 2018, divulgado pelo Instituto Nacional de Estudos e Pesquisas Educacionais Anísio Teixeira (INEP), a quantidade de novas matrículas, em cursos de graduação a distância, representa $40 \%$ do total de ingressantes em todo país. Em 2008, o mesmo indicador mostrava que essa porcentagem era de apenas $20 \%$.

\section{METODOLOGIA}

As instituições de ensino têm a capacidade de, no período de pandemia, abrir muitas oportunidades a partir do uso das ferramentas digitais disponíveis aplicadas no âmbito educacional para a realização de atividades como: reuniões, apresentações, debates, aulas, avaliações, cursos e entre outras atividades utilizando diversos meios digitais.

Na UFPB existem 7 grupos PET que possuem a necessidade de criação de material gráfico de qualidade, e devido a tais grupos não serem da área de design gráfico ou mídias digitais, existe a dificuldade em utilizar ferramentas de diagramação digital. Por este motivo, o grupo PET-Elétrica UFPB, por já ter experiência neste tipo de ferramenta gráfica, se disponibilizou em produzir um material de capacitação para esses grupos. Porém, com a suspensão das atividades presenciais devido ao coronavírus, o grupo teve que se adequar para fazer tal capacitação via EaD. 
Dessa forma, com o desafio de atender as necessidades estudantis, em maio de 2020, o grupo PET-Elétrica UFPB disponibilizou para a comunidade interna e externa à Universidade Federal da Paraíba o curso online do software Adobe InDesign.

Assim, foi realizada uma troca de conhecimento a partir da experiência do grupo PETElétrica na confecção de materiais e documentos utilizando a ferramenta de paginação digital. Além disso, observando a disponibilidade de recursos financeiros e materiais para serem utilizados e a procura pela experiência prática por parte dos outros 7 grupos da UFPB, surgiu a oportunidade de trabalhar realizando atividades de ensino e capacitação.

\subsection{Adobe InDesign}

A escolha da plataforma Adobe InDesign, que é um software de editoração eletrônica produzida pela Adobe Systems, foi feita graças a possibilidade de criar materiais didáticos e científicos que podem ser digitais ou até impressos. Esse programa é o mais utilizado para o desenvolvimento de atividades desse segmento e com ele é possível ter um controle preciso sobre a tipografia e ferramentas de criação, sendo viável também para adicionar interatividade ao seu trabalho, com a inclusão de animações e mídia avançada, como sons e vídeos. Sendo assim, satisfazendo as necessidades demandadas e entregando um resultado satisfatório.

Uma possível desvantagem do software InDesign é a não gratuidade, porém, a Adobe disponibiliza 7 dias grátis como forma de experiência e caso o usuário se familiarize com o programa, há a possibilidade de comprá-lo por meio de planos mensais e anuais que conta, inclusive, com condições especiais para alunos e professores.

\subsection{Curso de Adobe InDesign}

No panorama atual, o PET-Elétrica UFPB teve que se adequar ao ensino a distância e para isso, fez-se necessário um estudo acerca das metodologias utilizadas para abordar conteúdos por meio de aulas remotas. Assim, existiu a necessidade de um trabalho conjunto e intensivo entre professores tutores e alunos.

Num primeiro instante, por meio de reuniões, foi desenvolvida a ementa do curso de forma a propiciar aos participantes um melhor entendimento, visto que muitos deles não têm um contato constante com software e para corrigir isso, os conteúdos apresentados foram preparados para serem expostos de maneira simples, clara e objetiva, como forma de facilitar a relação de ensino-aprendizagem. Assim, uma característica fundamental que fortaleceu essa relação durante o curso foi a simplicidade das aulas.

Apresenta-se no Quadro 1 a ementa do curso planejado pelo grupo juntamente com os conteúdos abordados.

Quadro 1 - Ementa da capacitação no software InDesign.

\begin{tabular}{|c|c|}
\hline Tópico & Detalhamento \\
\hline Introdução ao InDesign & $\bullet \quad$ O que é o InDesign? \\
\hline
\end{tabular}




\begin{tabular}{|c|c|}
\hline & $\begin{array}{l}\text { - Como adquirir o InDesign? (pacotes } \\
\text { de experimentação, compra e } \\
\text { instalação). }\end{array}$ \\
\hline Primeiros passos & $\begin{array}{l}\text { - Procurando templates; } \\
\text { - Criando novos projetos (configurando } \\
\text { documento); } \\
\text { - Salvando e abrindo novos arquivos. } \\
\text { - Exportando PDF. }\end{array}$ \\
\hline Interface do programa & $\begin{array}{l}\text { - Comandos básicos da barra de } \\
\text { ferramentas e suas opções (seta, } \\
\text { zoom, texto, tesoura, objeto, entre } \\
\text { outros). }\end{array}$ \\
\hline Principais ferramentas & $\begin{array}{l}\text { - Trabalhando com página-mestre: } \\
\text { ○ O que é uma página mestre? } \\
\circ \text { Aplicando página-mestre; } \\
\text { ○ Editando página-mestre. } \\
\text { - Trabalhando com camadas. }\end{array}$ \\
\hline Inserindo recursos & - Inserindo imagens, textos e tabelas. \\
\hline
\end{tabular}

Fonte: autoria própria.

Depois de finalizada a ementa do curso, por meio do Google Formulários foi elaborado um questionário para a obtenção de dados para um melhor controle dos inscritos no curso, obtendose informações como: nome, e-mail pessoal, cidade e estado, universidade e grupo PET ou extensão que faça parte. Além disso, o método utilizado para a divulgação do curso para a comunidade acadêmica da Universidade Federal da Paraíba (UFPB) foi feita por meio do Gmail, email do Google, e para membros externos foi feita por email e redes sociais.

Logo após finalizar o preenchimento do formulário de inscrição, os participantes tinham acesso a dicas de como fazer o login, selecionar a opção turma e posteriormente, cadastrar o código da turma para assim, ter ingresso ao meio em que seria disponibilizado os materiais. Com isso, é perceptível que foi fundamental uma abordagem simples, porém detalhada e efetiva para atender os inscritos.

Os materiais disponibilizados para os alunos foram feitos por meio de vídeo aulas elaboradas a partir do uso de slides realizando a demonstração de todos os procedimentos, sendo este material disponibilizado para serem acessadas pela plataforma Google Classroom. Dentre as demais ferramentas online existentes, essa plataforma foi escolhida uma vez que o Centro de Energias Alternativas e Renováveis (CEAR) da UFPB possui uma parceria com o Gmail, além de o grupo PET-Elétrica e os alunos participantes da capacitação já terem familiaridade com o ambiente. Essa, além disso, oferece um serviço para alunos e professores por meio da criação de turmas virtuais o que facilita a comunicação e o compartilhamento de informações entre eles. 
Outro ponto importante para a escolha do Google Classroom se deu pelo seu fácil manuseio, acesso online e gratuito, e a possibilidade de tanto usá-lo em computadores ou celulares, quanto de possibilitar um acompanhamento satisfatório no que se refere ao tutor do ensino e ao aluno. Ao criar a turma, um código de acesso foi gerado pela própria ferramenta. Esse código foi disponibilizado para os participantes que, por meio dele, tiveram acesso às vídeoaulas e atividades propostas no curso já hospedadas na plataforma.

Ademais, como forma de solidificar o ensino, foi disponibilizada uma atividade final para que os alunos pudessem colocar em prática os conteúdos vistos durante o curso. Tal tarefa foi fundamentada na construção de uma revista de forma sucinta e que apresentasse a utilização de grande parte das ferramentas demonstradas nas aulas.

\section{RESULTADOS}

Na primeira experiência do grupo PET-Elétrica UFPB com o Ensino a Distância, o curso online de InDesign contou com um total de 71 inscritos. Desse total, 83\% dos participantes estudam na UFPB. Com relação ao alcance do curso, uma das vantagens do EaD é a inexistência do limite físico, então diversos alunos de outras cidades e estados se inscreveram. Além dos 57 alunos residentes em João Pessoa/PB é possível verificar na Figura 1, a representação gráfica da distribuição geográfica dos participantes.

Figura 1 - Cidades alcançadas com o curso.

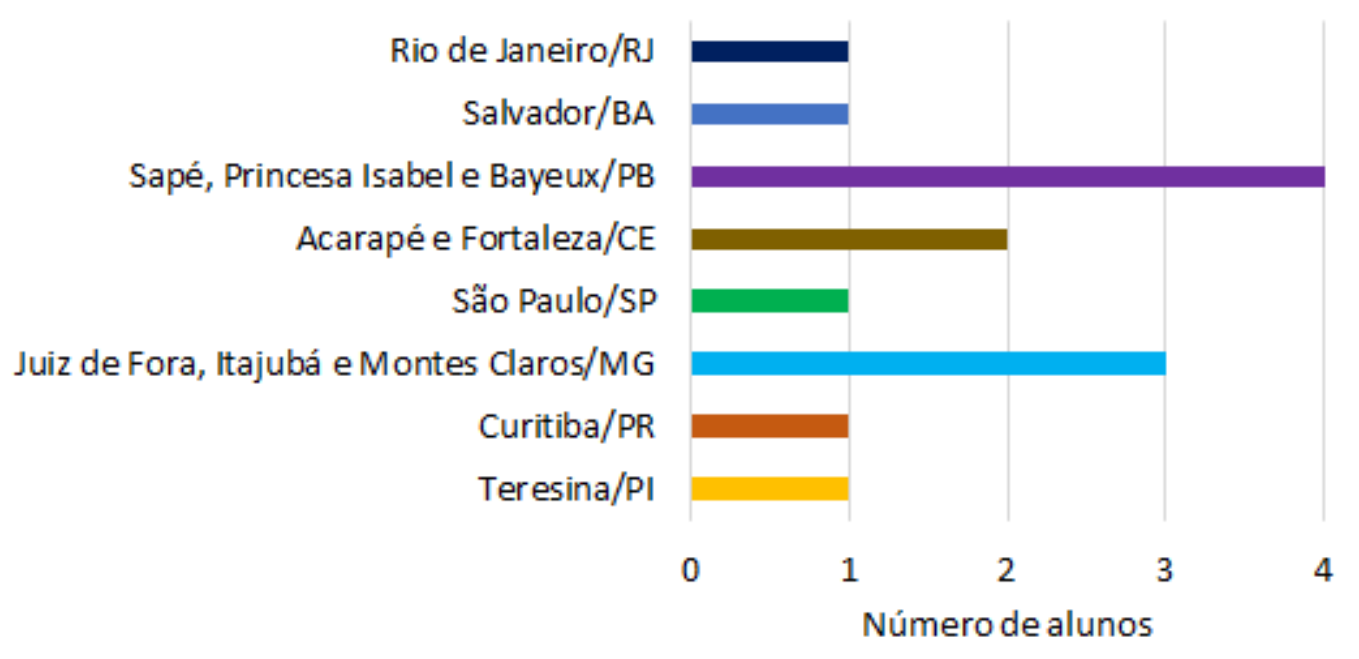

Fonte: autoria própria.

Além disso, como pode ser visto na Figura 2, os estudantes, no geral, qualificaram a comunicação com os ministrantes como boa, e compreenderam bem o conteúdo ministrado. $\mathrm{O}$ que é um resultado positivo, visto que a limitação do contato professor/aluno pode muitas vezes limitar a compreensão do estudante, já que ele não pode tirar dúvidas na hora em que está vendo o conteúdo, tendo que muitas vezes mandar emails e esperar por respostas. 


\section{COBENGE C. COBENCE 2020

Figura 2 - Resultados da pesquisa de satisfação referente à comunicação com ministrantes e compreensão do conteúdo.

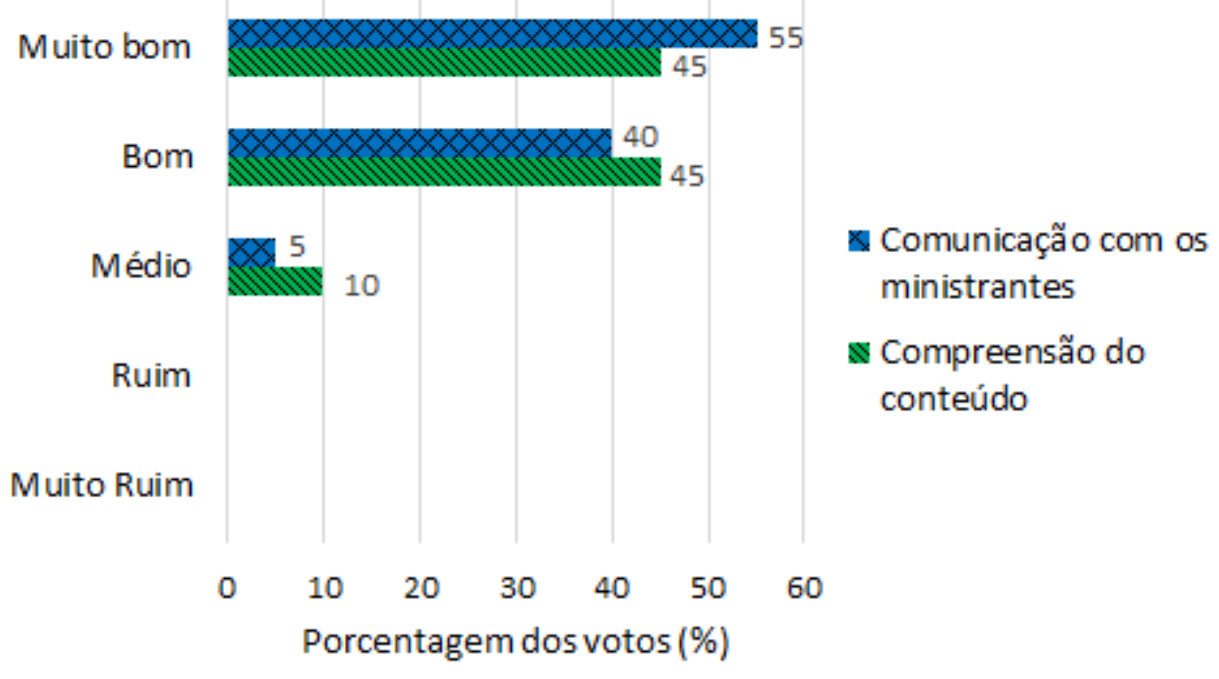

Fonte: autoria própria.

Na Figura 3, apresenta-se o resultado da consulta realizada com os estudantes avaliando os seguintes pontos: a qualidade das aulas, a plataforma utilizada e a atividade final. Assim, podese verificar que $70 \%$ dos estudantes avaliaram a qualidade das aulas como boa, $65 \%$ avaliaram a plataforma positivamente, e $75 \%$ avaliaram a atividade final também de forma positiva.

Figura 3 - Resultados da pesquisa de satisfação referente à qualidade das aulas, plataforma utilizada e atividade final.

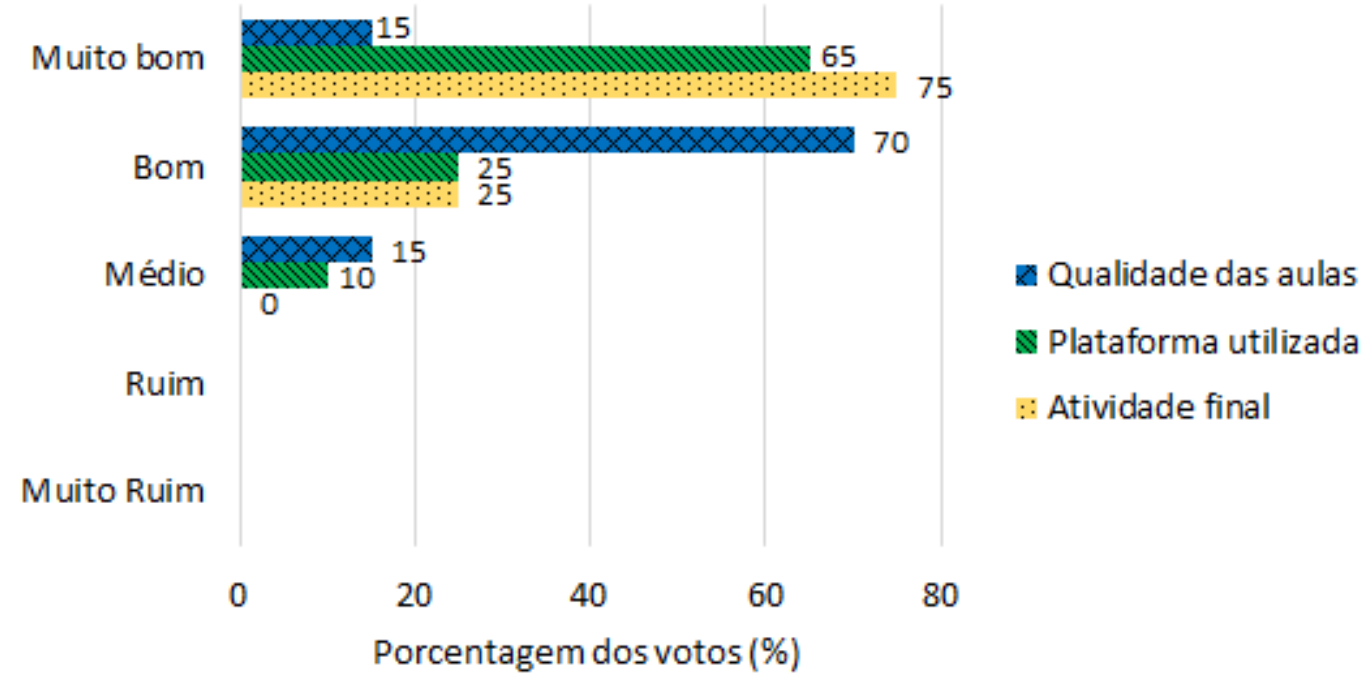

Fonte: autoria própria. 
Além disso, 95\% dos participantes informaram que, de acordo com a experiência com o curso em questão, eles fariam outros cursos na modalidade EaD no futuro, e ainda, $100 \%$ dos candidatos informaram que o conteúdo ministrado ajudará no seu desenvolvimento acadêmico e profissional.

\section{CONCLUSÕES}

Com os resultados obtidos, a primeira experiência do grupo PET-Elétrica com o ensino a distância (EaD) mostrou-se eficaz, uma vez que, no presente período de pandemia, o curso online do software InDesign permitiu a participação da comunidade estudantil promovendo assim, a fácil aprendizagem e a disseminação de conhecimento.

Além disso, como essa atividade atingiu um público de outros estados brasileiros, a ação de extensão por meio do curso promoveu o contato entre as instituições brasileiras de ensino, preservando e criando novas estratégias para a manutenção da educação em todos os níveis.

Portanto, a realização do curso online de InDesign não só deixou para os participantes o conhecimento acerca do software, como também forneceu aos ministrantes dados para validar a forma como a atividade foi desenvolvida e possibilitar melhorias em capacitações nesse tipo de modalidade, assim, possibilitando um melhor andamento das futuras atividades do grupo PET-Elétrica.

\section{REFERÊNCIAS}

ABED. CensoEAD.BR: Relatório analítico da aprendizagem a distância no Brasil 2018. Curitiba: $\quad$ Intersaberes, $2019 . \quad$ Disponível em:http:<http://www.abed.org.br/site/pt/midiateca/censo_ead/1644/2019/10/censoeadbr_2018/2019>. Acesso em: 23 de mai. 2020.

ANDERSON, R. M.; HEESTERBEEK, H.; KLINKENBERG, D.; HOLLINGSWORTH, T. D. How will country-based mitigation measures influence the course of the COVID-19 epidemic? The Lancet, Londres, v.395, n.10228, p. 931-934, 2020.

BRASIL. Ministério da Educação. Gabinete do Ministro. Portaria no 544, de 16 de junho de 2020. Dispõe sobre a substituição das aulas presenciais por aulas em meios digitais, enquanto durar a situação de pandemia do novo coronavírus - Covid-19, e revoga as Portarias MEC $\mathrm{n}^{\circ}$ 343, de 17 de março de 2020, nº 345, de 19 de março de 2020, e n⿳ 473, de 12 de maio de 2020. Diário Oficial da União, Brasília, DF. Disponível em: <http://www.in.gov.br/en/web/dou//portaria-n-544-de-16-de-junho-de-2020-261924872>. Acesso em 27 de jul. 2020.

BROOKS, S.; WEBSTER, R.; SMITH, L.; WOODLAND, L.; WESSELY, S.; GREENBERG, N.; RUBIN, G. The psychological impact of quarantine and how to reduce it: rapid review of the evidence. The Lancet, Londres, v.395, n.10227, p. 912-920, 2020.

COHEN, J.; NORMILE, D. New SARS-like virus in China triggers alarm. Revista Science, Nova York, v.367, n.6475, p. 234-235, 2020. 
COWLING, J. B.; ALI, S. T.; Ng, T. W. Y.; TSANG, T. K.; LI, J. C. M.; FONG, M. W.; LIAO, Q.; KWAN, M. Y. W.; LEE, S. L.; CHIU, S.; WU, J.; WU, P.; LEUNG, G. Impact assessment of non-pharmaceutical interventions against coronavirus disease 2019 and influenza in Hong Kong: an observational study. Lancet Public Health, Londres, v.5 n.5, p. 279-288, 2020.

FREIRE. Paulo. Pedagogia da autonomia: saberes necessários à prática educativa. São Paulo: Paz e Terra, 1996. Coleção leitura, p.12, 2002.

INEP. Censo da educação superior 2018. Brasília: INEP/Ministério da Educação. Disponível em:<https://www.inep.gov.br>. Acesso em: 23 de mai. 2020.

KISSLER, S. M.; TEDIJANTO, C.; GOLDSTEIN, E.; GRAD, Y. H.; LIPSITCH, M. Projecting the transmission dynamics of SARS-CoV-2 through the postpandemic period. Revista Science, Nova York, v.368, n.6493, p. 860-868, 2020.

Ministério da Educação. CNE aprova diretrizes para escolas durante pandemia. Portal MEC, 2020. Disponível em: <http://portal.mec.gov.br/component/content/article/12noticias/acoes-programas-e-projetos-637152388/89051-cne-aprova-diretrizes-para-escolasdurante-a-pandemia?Itemid=164>. Acesso em: 23 de mai. 2020.

Ministério da Saúde. O que é COVID-19. Disponível em:

https://coronavirus.saude.gov.br/sobre-a-doenca\#o-que-e-covid. Acesso em: 22 mai. 2020.

Organização Pan-Americana da Saúde. Folha informativa - COVID-19 (doença causada pelo novo coronavírus). Disponível em:

https://www.paho.org/bra/index.php?option=com_content\&view=article\&id=6101:covid19\&I temid=875. Acesso em: 22 mai. 2020.

SANTOS, J. F. S. Avaliação no Ensino a Distância. Revista Ibero-Americana, São Paulo, v.38, n.4, p. 1-9, 2006.

UNESCO. Suspensão das aulas e resposta à COVID-19. Disponível em: <https://pt.unesco.org/covid19/educationresponse>. Acesso em: 23 de mai. 2020.

WEST, R.; MICHIE, S.; RUBIN, G. J.; AMLÔT, R. Applying principles of behaviour change to reduce SARS-CoV-2 transmission. Nature - Human Behaviour, Londres, v.4, n.5, p. 451459, 2020. 


\title{
EXPERIENCE OF THE GROUP PET-ELÉTRICA UFPB WITH DISTANCE LEARNING: ADAPTATION OF TEACHING IN PANDEMIC TIMES
}

\begin{abstract}
Due to the rapid emergence of a pandemic in the year 2020, caused by the new coronavirus, it was necessary for the population in general, including students and teachers, to take measures of isolation and social distance. Due to the momentary impossibility of attending presential classes, universities and learning environments face the new challenge of adapting teaching to current circumstances. Thus, this work aims to analyze the use of Distance Learning, its advantages and disadvantages, based on the online course offered by the group PET-Elétrica UFPB, of training in the InDesign software, analyzing data collected through online forms.
\end{abstract}

Keywords: Distance Learning, Pandemic, Tutorial Education Program - PET, Education, Social Isolation. 